\title{
Aldosterone-to-renin ratio and home blood pressure in subjects with higher and lower sodium intake: the Ohasama Study
}

\author{
Michihiro Satoh $^{1}$, Masahiro Kikuya ${ }^{1}$, Azusa Hara ${ }^{2}$, Takayoshi Ohkubo ${ }^{1,3}$, Takefumi Mori ${ }^{4}$, Hirohito Metoki ${ }^{1,5}$, \\ Megumi T Utsugi ${ }^{6}$, Takuo Hirose ${ }^{1}$, Taku Obara ${ }^{1,7}$, Ryusuke Inoue ${ }^{8}$, Kei Asayama ${ }^{1}$, Kazuhito Totsune ${ }^{1,9}$, \\ Haruhisa Hoshi ${ }^{10}$, Hiroshi Satoh ${ }^{11}$ and Yutaka Imai ${ }^{1}$
}

Aldosterone-to-renin ratio (ARR) is used to screen primary hyperaldosteronism. We investigated the association between ARR and the prevalence of hypertension using home blood pressure (HBP) measurements in community residents stratified for long-term habitual dietary sodium intake. We obtained HBP and conventional blood pressure (CBP) data for 514 participants aged $\geqslant 35$ years not receiving antihypertensive treatment in the general population of Ohasama (mean age: $59.7 \pm 10.8$ years; $71.2 \%$ women). A standardized method was used to calculate habitual sodium intake from a food-frequency questionnaire. The prevalence of HBP hypertension ( $\geqslant 135 / 85 \mathrm{~mm} \mathrm{Hg}$ ) and CBP hypertension ( $\geqslant 140 / 90 \mathrm{~mm} \mathrm{Hg}$ ) were 12.6 and $20.2 \%$, respectively. The median plasma renin activity (PRA), plasma aldosterone concentration (PAC) and ARR were $1.1 \mathrm{ng} \mathrm{ml}^{-1} \mathrm{~h}^{-1}$, $6.4 \mathrm{ng}$ per $100 \mathrm{ml}$ and $5.5 \mathrm{ng}$ per $100 \mathrm{ml}^{\text {per ng ml}} \mathrm{h}^{-1} \mathrm{~h}^{-1}$, respectively. After adjustment for possible confounding factors, each 1 s.d. increase in logARR was associated with the prevalence of HBP hypertension (odds ratio $1.37 ; P=0.04$ ), but not with the prevalence of CBP hypertension $(P=0.2)$. The association of ARR with HBP hypertension was strengthened for subjects with high sodium intake (greater than or equal to the median of $4822 \mathrm{mg} \mathrm{day}^{-1}$ ), whereas it became nonsignificant for those with low sodium intake (interaction $P=0.03$ ). Among subjects with high sodium intake, HBP hypertensives had significantly lower PRA than normotensives, despite no differences in PAC. In conclusion, relative aldosterone excess or low-renin hypertension may have an important role in HBP hypertension in the general population with high sodium intake.

Hypertension Research (2011) 34, 361-366; doi:10.1038/hr.2010.236; published online 2 December 2010

Keywords: aldosterone excess; aldosterone-to-renin ratio; epidemiology; low-renin hypertension; sodium-sensitive hypertension

\section{INTRODUCTION}

Aldosterone has been implicated in the pathogenesis of hypertension in several experimental and clinical studies. Many studies ${ }^{1-5}$ have indicated a positive association between aldosterone and hypertension; others $^{6-8}$ have shown that hypertensive patients had normal ${ }^{6,8}$ or low ${ }^{7}$ aldosterone levels compared with values in normotensive subjects. One of the reasons for these inconsistent results could be the confounding effect of antihypertensive medications, differences in time of blood sampling, body position and dietary sodium intake, which significantly affect aldosterone levels. ${ }^{9,10}$ In most studies, longterm dietary sodium intake has not been considered. Most studies ${ }^{1,3-8}$ use spot urine samples, ${ }^{1,7,8} 24$-h urine collection ${ }^{4,6}$ and short-term dietary sodium restriction; ${ }^{5,6}$ only one study ${ }^{3}$ measured long-term habitual sodium intake using a dietary record. To evaluate the longterm effect of dietary sodium intake, we surveyed habitual dietary sodium intake.

The aldosterone-to-renin ratio (ARR) is believed to be a more robust screening test than aldosterone levels for primary aldosteronism, and could be an index for inappropriate aldosterone activity and salt sensitivity. ${ }^{9,11}$ However, limited information ${ }^{2,3}$ is available on the association of ARR with hypertension.

All the above-mentioned studies ${ }^{1-8}$ were based solely on conventional blood pressure (CBP) measurements. No studies have investigated the association between ARR and hypertension using home

\footnotetext{
${ }^{1}$ Department of Planning for Drug Development and Clinical Evaluation, Tohoku University Graduate School of Pharmaceutical Sciences, Sendai, Japan; ${ }^{2}$ Division of Epidemiology and Prevention, Research Center for Cancer Prevention and Screening National Cancer Center, Tokyo, Japan; ${ }^{3}$ Department of Health Science, Shiga University of Medical Science, Ohtsu, Japan; ${ }^{4}$ Division of Nephrology, Endocrinology, and Vascular Medicine, Department of Medicine, Tohoku University Graduate School of Medicine, Sendai, Japan; ${ }^{5}$ Department of Obstetrics and Gynecology, Tohoku University Graduate School of Medicine, Sendai, Japan; ${ }^{6}$ National Institute of Health and Nutrition, Tokyo, Japan; ${ }^{7}$ Department of Pharmacy, Tohoku University Hospital, Sendai, Japan; ${ }^{8}$ Medical Informatics, Tohoku University Hospital, Sendai, Japan; ${ }^{9}$ Department of Social Welfare, Faculty of Synthetic Welfare, Tohoku Fukushi University, Sendai, Japan; ${ }^{10}$ Ohasama Hospital, Iwate, Japan and ${ }^{11}$ Department of Environmental Health Sciences, Tohoku University Graduate School of Medicine, Sendai, Japan

Correspondence: Dr M Kikuya, Department of Planning for Drug Development and Clinical Evaluation, Tohoku University Graduate School of Pharmaceutical Sciences, 6-3 Aramaki-aza-Aoba, Aoba-ku, Sendai 980-8578, Japan.

E-mail: kikuyam@m.tains.tohoku.ac.jp
}

Received 13 May 2010; revised 30 August 2010; accepted 23 September 2010; published online 2 December 2010 
blood pressure (HBP) measurements, which are reportedly more reliable than CBP and avoid both observer and regression dilution biases. ${ }^{12}$ HBP measurements eliminate the white-coat effect, ${ }^{12}$ offer more prognostic significance than CBP measurements ${ }^{13}$ and are more indicative of target organ damage. ${ }^{14}$

The objective of this cross-sectional study was to investigate the association between ARR and the prevalence of hypertension using HBP measurements in community residents stratified for long-term dietary sodium intake, as assessed by a food-frequency questionnaire.

\section{METHODS}

\section{Design}

This investigation was a part of the Ohasama study. The socioeconomic and demographic characteristics of this region and details of the study project have been described previously. ${ }^{13,15}$ The institutional review boards of Tohoku University School of Medicine and the Department of Health of the Ohasama Municipal Government approved the study.

\section{Study population}

In 1997, the population of Ohasama included 7318 subjects. Of those, 4992 were $\geqslant 35$ years old, and 2719 had a health check-up that year. Subjects ( $n=888$ ) who did not undergo a health check-up were ineligible. Of the 1831 eligible individuals, 1350 subjects ( $74 \%$, mean age: $61.5 \pm 11.2$ years; $65 \%$ women) gave informed consent and participated in the present study. For the current analysis, we excluded 597 individuals who did not measure their morning HBP $\geqslant 3$ times. ${ }^{16}$ Furthermore, we excluded 228 subjects treated with antihypertensive drugs because of the effects of antihypertensive medications on the renin-angiotensin system. ${ }^{17}$ We also excluded 11 subjects because of insufficient data on nutrient intake. Therefore, 514 subjects were included in the analyses of HBP hypertension. We did not perform adrenal computed tomography scan, because primary aldosteronism was not suspected in any subjects. The 514 subjects were significantly younger and comprised a higher proportion of women than the excluded individuals.

\section{BP measurements}

Physicians and/or public health nurses instructed participants on how to perform HBP measurements. Participants were asked to measure their BP once every morning over 4 weeks using an oscillometric device ${ }^{18}$ (HEM701C, Omron Healthcare, Kyoto, Japan) within $1 \mathrm{~h}$ of waking, with measurements performed in a sitting position after $>2$ min of rest. ${ }^{19}$ The HBP of an individual was defined as the mean of all measurements obtained for that person.

CBP was measured twice consecutively during the health check-up held from 0900 to $1100 \mathrm{~h}$ or from 1300 to $1500 \mathrm{~h}$. Measurements were taken by nurses or technicians at local medical centers using an automatic USM-700F sphygmomanometer ${ }^{18}$ (UEDA Electronic Works, Tokyo, Japan) based on the Korotkoff sound technique. All measurements were taken with subjects in the sitting position, after a minimum of 2-min rest. The mean of the two readings was defined as the CBP.

We defined HBP hypertension as BP $\geqslant 135 \mathrm{~mm} \mathrm{Hg}$ systolic or $\geqslant 85 \mathrm{~mm} \mathrm{Hg}$ diastolic; CBP hypertension was defined as BP $\geqslant 140 \mathrm{~mm} \mathrm{Hg}$ systolic or $\geqslant 90 \mathrm{~mm} \mathrm{Hg}$ diastolic.

\section{Physical and biochemical examinations}

Blood for measurement of plasma renin activity (PRA, ng ml${ }^{-1} \mathrm{~h}^{-1}$ ) and plasma aldosterone concentrations (PAC, ng per $100 \mathrm{ml}$ ) was drawn with subjects in a sitting position after $\sim 30 \mathrm{~min}$ of rest, between 0900 and $1100 \mathrm{~h}$ or between 1300 and $1500 \mathrm{~h}$; most subjects had not fasted. Blood was collected in chilled EDTA tubes and measured by radioimmunoassay (SRL, Tokyo, Japan). The interassay coefficients of variation were $10.5 \%$ at $1.5 \mathrm{ng} \mathrm{ml}^{-1} \mathrm{~h}^{-1}$ for PRA and $4.55 \%$ at $8.98 \mathrm{ng}$ per $100 \mathrm{ml}$ for PAC. The intraassay coefficients of variation were $7.78 \%$ at $1.25 \mathrm{ng} \mathrm{m}^{-1} \mathrm{~h}^{-1}$ for PRA and $4.81 \%$ at $8.95 \mathrm{ng}$ per $100 \mathrm{ml}$ for PAC. The lower limits of detections were $0.1 \mathrm{ng} \mathrm{ml}^{-1} \mathrm{~h}^{-1}$ for PRA and $1 \mathrm{ng}$ per $100 \mathrm{ml}$ for PAC. Hypercholesterolemia was defined as total cholesterol $\geqslant 5.68 \mathrm{mmoll}^{-1}$ $(\geqslant 220 \mathrm{mg}$ per $100 \mathrm{ml})$, use of medication for hypercholesterolemia and/or a history of hypercholesterolemia. Diabetes mellitus was defined as a random blood glucose level $\geqslant 11.11 \mathrm{mmoll}^{-1}$ ( $\geqslant 200 \mathrm{mg}$ per $100 \mathrm{ml}$ ), HbAlc level $\geqslant 6.5 \%$, use of medication for diabetes and/or a history of diabetes mellitus. ${ }^{20}$

\section{Long-term sodium and potassium intakes}

A standardized method was used to calculate food consumption and related nutrients from data obtained in a Japanese version of the food-frequency questionnaire, which asked about the average frequency of consumption of each food during the previous year. ${ }^{21}$ We previously confirmed that the foodfrequency questionnaire is reasonably reproducible and comparable with diet records, taking into account seasonal variations in food consumption. ${ }^{21} \mathrm{~A}$ standard portion size of one serving was specified for each food, and respondents were asked if their usual portion was larger ( $>1.5$ times), the same or smaller ( $<0.5$ times) than the standard. We then estimated sodium and potassium intakes. ${ }^{21,22}$ Estimated GFR (eGFR) was estimated from the serum creatinine using a Japanese equation. ${ }^{23}$

\section{Statistical analysis}

PRA activity, PAC and ARR were natural log-transformed because of their positively skewed distributions. To analyze the relationship between tertiles of ARR and subject characteristics, we compared means and proportions using analysis of variance and the $\chi^{2}$-test for univariate analysis. For computing sexand age-adjusted $P$-values, we used analysis of covariance and logistic regression analysis as appropriate. We examined the association of PRA, PAC and ARR with the prevalence of hypertension after adjustment for sex and age (adjusted model) using logistic regression analysis. In addition to the adjusted model, we further accounted for body mass index (BMI), smoking and drinking status, hypercholesterolemia, diabetes mellitus, history of cardiovascular disease, serum sodium and tertiles of dietary sodium intake (fully adjusted model). To test for the effect of dietary sodium, we stratified subjects according to sodium intake (low, less than median of $4822 \mathrm{mg} \mathrm{day}^{-1}$; high, greater than or equal to median). We also determined the significance of the interaction between sodium intake and ARR. Data are expressed as mean \pm s.d. unless otherwise noted. SAS version 9.1 software (SAS Institute, Cary, NC, USA) was used for statistical analysis.

\section{RESULTS}

\section{Participant characteristics}

The 514 participants included 366 women (71.2\%) and 65 patients with HBP hypertension (12.6\%). Participants were $59.7 \pm 10.8$ years old, had a BMI of $23.3 \pm 2.9 \mathrm{~kg} \mathrm{~m}^{-2}$ and a total cholesterol level of $5.06 \pm 0.86 \mathrm{mmol}^{-1}$. At enrollment, 62 participants (12.1\%) were current smokers, $182(35.4 \%)$ reported intake of alcohol, 139 (27.0\%) had hypercholesterolemia, $33(6.4 \%)$ had diabetes mellitus and $19(3.7 \%)$ had a history of cardiovascular disease. Two subjects $(0.4 \%)$ had ARR $\geqslant 20 \mathrm{ng}$ per $100 \mathrm{ml}$ per $\mathrm{ng} \mathrm{m}^{-1} \mathrm{~h}^{-1}$ in the presence of PAC $\geqslant 15 \mathrm{ng}$ per $100 \mathrm{ml}$, which was the cutoff value to screen for primary aldosteronism; ${ }^{24,25}$ however, neither subject had hypertension or hypokalemia. The mean number of measurements for HBP was $23.2 \pm 6.0$, and the mean systolic/diastolic HBP and CBP values of subjects were 117.2 $\pm 13.6 / 73.2 \pm 8.8$ and $128.9 \pm 13.1$ / $72.1 \pm 8.9 \mathrm{~mm} \mathrm{Hg}$, respectively. The HBP was significantly correlated with CBP in all subjects ( $r=0.54$ for systolic BP, $r=0.50$ for diastolic $\mathrm{BP}$ ), and in subjects with HBP hypertension ( $r=0.40$ for systolic BP, $r=0.35$ for diastolic BP).

The median (25-75th percentiles) PRA level was 1.1 (0.7-1.7) $\mathrm{ng} \mathrm{ml}^{-1} \mathrm{~h}^{-1}$, the median PAC level was $6.4(4.8-8.2) \mathrm{ng}$ per $100 \mathrm{ml}$ and the median ARR level was 5.5 (3.5-9.0) ng per $100 \mathrm{ml}^{\text {per }} \mathrm{ng} \mathrm{ml}^{-1} \mathrm{~h}^{-1}$. The proportion of women and the levels of BMI, HBP and serum sodium significantly increased with increases in ARR (Table 1). Among the 514 study subjects, we obtained home heart rate in 501 subjects, of whom 63 were HBP hypertensives. The levels of home heart rate significantly decreased with increases in ARR (67.3 \pm 7.3 , 
Table 1 Clinical characteristics among groups classified by tertiles of ARR

\begin{tabular}{|c|c|c|c|c|c|}
\hline \multirow[b]{2}{*}{ Characteristic } & \multicolumn{5}{|c|}{ Tertiles of ARR } \\
\hline & $<4.22(\mathrm{n}=171)$ & $4.22-7.40(n=170)$ & $\geqslant 7.40(n=173)$ & P-value & Sex- and age- adjusted $\mathrm{P}$-value \\
\hline Women, \% & 60.2 & 73.5 & 79.8 & 0.0002 & \\
\hline Age, years & $60.3 \pm 10.9$ & $59.3 \pm 10.6$ & $59.3 \pm 10.9$ & 0.6 & \\
\hline BMI, $\mathrm{kg} \mathrm{m}^{-2}$ & $22.6 \pm 2.8$ & $23.4 \pm 3.0$ & $23.8 \pm 3.1$ & 0.001 & 0.0009 \\
\hline $\mathrm{BMI} \geqslant 25 \mathrm{~kg} \mathrm{~m}^{-2}, \%$ & 15.8 & 30.6 & 33.0 & 0.0005 & 0.0002 \\
\hline Past history of CVD, \% & 4.7 & 2.9 & 3.5 & 0.7 & 0.8 \\
\hline Diabetes, \% & 5.8 & 7.1 & 6.4 & 0.9 & 0.9 \\
\hline Hypercholesterolemia, \% & 25.7 & 25.9 & 29.5 & 0.7 & 0.7 \\
\hline Smoking, \% & 14.6 & 14.7 & 6.9 & 0.04 & 0.9 \\
\hline Drinking, \% & 42.1 & 34.1 & 30.1 & 0.06 & 0.3 \\
\hline \multicolumn{6}{|l|}{$H B P$} \\
\hline Systolic, mm Hg & $116.2 \pm 15.1$ & $116.5 \pm 11.9$ & $119.0 \pm 13.6$ & 0.1 & 0.001 \\
\hline Diastolic, mm Hg & $72.1 \pm 9.5$ & $73.2 \pm 7.5$ & $74.4 \pm 9.0$ & 0.047 & $<0.0001$ \\
\hline Hypertension, \% & 12.3 & 9.4 & 16.2 & 0.2 & 0.02 \\
\hline \multicolumn{6}{|l|}{$C B P$} \\
\hline Systolic, mm Hg & $128.0 \pm 14.3$ & $128.8 \pm 12.1$ & $129.9 \pm 12.7$ & 0.4 & 0.06 \\
\hline Diastolic, mm Hg & $71.4 \pm 9.9$ & $72.1 \pm 7.3$ & $72.7 \pm 9.3$ & 0.4 & 0.1 \\
\hline Hypertension, \% & 20.5 & 15.9 & 24.3 & 0.2 & 0.1 \\
\hline \multicolumn{6}{|l|}{ Biochemical measurements } \\
\hline $\mathrm{HbA} 1 \mathrm{c}, \%$ & $5.15 \pm 0.66$ & $5.12 \pm 0.63$ & $5.13 \pm 0.58$ & 0.6 & 0.9 \\
\hline Total cholesterol, mg per $100 \mathrm{ml}$ & $193.7 \pm 33.1$ & $198.4 \pm 33.6$ & $196.3 \pm 33.1$ & 0.4 & 0.6 \\
\hline eGFR, $\mathrm{ml} \mathrm{min}-1$ per $1.73 \mathrm{~m}^{2}$ & $87.5 \pm 19.9$ & $84.3 \pm 18.3$ & $87.6 \pm 17.9$ & 0.2 & 0.09 \\
\hline Uric acid, mg per $100 \mathrm{ml}$ & $4.21 \pm 1.16$ & $4.00 \pm 1.16$ & $3.94 \pm 1.12$ & 0.07 & 0.9 \\
\hline Serum sodium, mEq I-1 & $141.9 \pm 1.8$ & $142.1 \pm 1.6$ & $142.4 \pm 1.6$ & 0.02 & 0.04 \\
\hline Serum potassium, $\mathrm{mEq} \mathrm{I}^{-1}$ & $4.29 \pm 0.36$ & $4.32 \pm 0.35$ & $4.36 \pm 0.34$ & 0.2 & 0.1 \\
\hline \multicolumn{6}{|l|}{ Dietary intake } \\
\hline Energy, kcal day ${ }^{-1}$ & $2031 \pm 895$ & $1878 \pm 672$ & $1940 \pm 747$ & 0.3 & 0.5 \\
\hline Sodium, mg day ${ }^{-1}$ & $6358 \pm 6140$ & $5219 \pm 3979$ & $5754 \pm 3742$ & 0.1 & 0.048 \\
\hline Salt, g day ${ }^{-1}$ & $16.0 \pm 15.5$ & $13.1 \pm 10.1$ & $14.5 \pm 9.5$ & 0.09 & 0.04 \\
\hline Potassium, mg day ${ }^{-1}$ & $2978 \pm 2492$ & $2665 \pm 1728$ & $2808 \pm 1593$ & 0.4 & 0.3 \\
\hline Sodium/potassium & $2.13 \pm 0.93$ & $1.93 \pm 0.75$ & $2.07 \pm 0.90$ & 0.06 & 0.04 \\
\hline
\end{tabular}

Abbreviations: BMI, body mass index; CBP, conventional blood pressure; CVD, cardiovascular disease; eGFR, estimated glomerular filtration rate; HbAlc, glycated hemoglobin; HBP, home blood pressure.

eGFR was estimated from the serum creatinine value using a Japanese equation: eGFR $\left(\mathrm{ml} \mathrm{min}^{-1}\right.$ per $\left.1.73 \mathrm{~m}^{2}\right)=194 \times \mathrm{Age}^{-0.287} \times \mathrm{S}-\mathrm{Cr}^{-1.094}($ if female $\times 0.739){ }^{23}$

Home hypertension and CBP hypertension were at least $135 / 85$ and $140 / 90 \mathrm{~mm} \mathrm{Hg}$, respectively.

$65.2 \pm 8.9$ and $65.2 \pm 8.7$ beats $\mathrm{min}^{-1}$ for ascending tertiles, $P$ for trend $=0.03$ ), whereas this association was not observed in HBP hypertensives $\left(65.8 \pm 8.8,66.1 \pm 8.1\right.$ and $63.0 \pm 14.9$ beats $\mathrm{min}^{-1}$ for ascending tertiles, $P$ for trend $=0.5)$. No other variables showed a consistent association with ARR. There was no correlation between $\log \mathrm{PAC}$ and serum potassium $(r=0.06, P=0.2)$ or between $\log \mathrm{PAC}$ and BMI $(r=0.01, P=0.9)$ in any subject. Similarly, in HBP hypertensives, $\log \mathrm{PAC}$ was not correlated with either serum potassium or BMI $(|r| \leqslant 0.10, P \leqslant 0.5)$.

\section{LogARR and prevalence of hypertension}

Of the 514 study subjects, 65 (12.6\%) had HBP hypertension, and 104 (20.2\%) had CBP hypertension. A 1 s.d. increase in logARR was significantly associated with the prevalence of HBP hypertension (odds ratio (OR) 1.37; 95\% confidence interval (CI) 1.01-1.86; $P=0.04$ ) in fully adjusted models (Table 2). LogPRA showed a marginally significant relation with hypertension (odds ratio 0.76; 95\% confidence interval $0.56-1.02 ; P=0.07$ ). On the other hand, $\log$ PAC was not associated with hypertension. When HBP of an individual was defined as the mean of two measurements for the initial 2 days, similar results were obtained (data not shown). We did not find any significant associations between $\log P R A, \log P A C$ or $\operatorname{logARR}$ and CBP hypertension $(P \geqslant 0.2)$.

To compare HBP and CBP in terms of predictive power of ARR, we performed a multiple regression model including $\log A R R$ as the dependent variable and HBP level, CBP level and other confounding factors as independent variables. LogARR was predicted by HBP levels ( $P=0.01$ for systolic BP, $P=0.0004$ for diastolic $\mathrm{BP}$ ), but not by $\mathrm{CBP}$ levels $(P=0.5$ for systolic $\mathrm{BP}, P=0.8$ for diastolic $\mathrm{BP}$ ).

\section{Interaction between $\log A R R$ and sodium intake on HBP hypertension}

We stratified subjects by median sodium intake $\left(4822 \mathrm{mg} \mathrm{day}^{-1}\right)$. The associations of lower $\log$ PRA and higher $\log$ ARR with an increased prevalence of HBP hypertension were strengthened for subjects with high sodium intake, whereas they became nonsignificant for those 
Table 2 ORs for prevalence of hypertension per s.d. increase in LogPRA, LogPAC and LogARR

OR $(95 \% \mathrm{Cl})$ for prevalence of hypertension

\begin{tabular}{|c|c|c|c|c|c|c|c|}
\hline Dependent variable & Independent variable & \\
\hline \multicolumn{8}{|l|}{ HBP hypertension } \\
\hline & $\log P R A$ & $0.83(0.64-1.08)$ & 0.2 & $0.74(0.56-0.98)$ & 0.04 & $0.76(0.56-1.02)$ & 0.07 \\
\hline & $\log A R R$ & $1.11(0.86-1.44)$ & 0.4 & $1.37(1.03-1.82)$ & 0.03 & $1.37(1.01-1.86)$ & 0.04 \\
\hline \multicolumn{8}{|l|}{ CBP hypertension } \\
\hline & $\log A R R$ & $1.10(0.89-1.37)$ & 0.4 & $1.19(0.95-1.50)$ & 0.1 & $1.16(0.91-1.47)$ & 0.2 \\
\hline
\end{tabular}

Abbreviations: ARR, aldosterone-to-renin ratio; BMI, body mass index; CBP, conventional blood pressure; Cl, confidence interval; CVD, cardiovascular disease; HBP, home blood pressure; OR, odds ratio; PAC, plasma aldosterone concentration; PRA, plasma renin activity.

The fully adjusted model was accounted for sex, age, BMI, habitual smoking, habitual drinking, diabetes mellitus, hypercholesterolemia, past history of cardiovascular disease, serum sodium and salt intake.

Home hypertension and CBP hypertension were at least $135 / 85$ and $140 / 90 \mathrm{~mm} \mathrm{Hg}$, respectively.

Of the 514 study subjects, 65 (12.6\%) had HBP hypertension and 104 (20.2\%) had CBP hypertension.

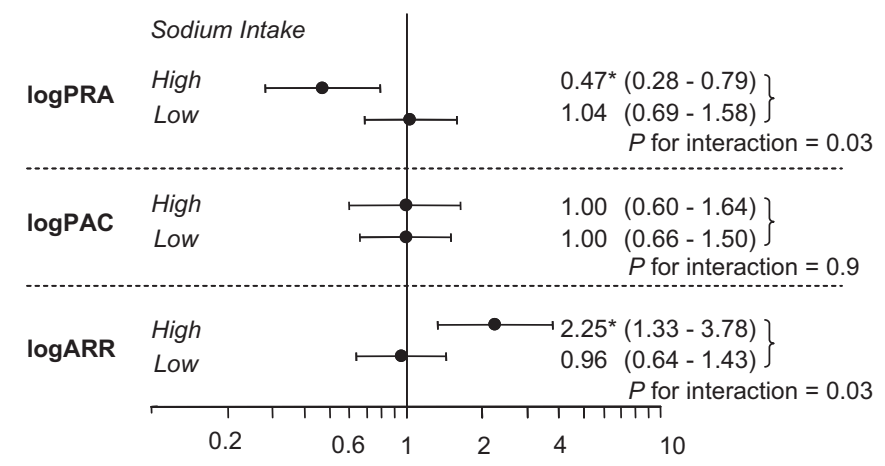

Figure 1 Association of plasma renin activity (PRA), plasma aldosterone concentration (PAC) and aldosterone-to-renin ratio (ARR) with the prevalence of home blood pressure (HBP) hypertension by median of sodium intake. Adjusted odds ratio (95\% confidence intervals) for prevalence of HBP hypertension per 1 s.d. increase in $\log P R A, \log P A C$ and IogARR by median sodium intake (4822 $\left.\mathrm{mg} \mathrm{day}^{-1}\right)$. Home hypertension was at least 135/ $85 \mathrm{~mm} \mathrm{Hg}$. Odds ratios for prevalence of HBP hypertension were adjusted for sex, age, body mass index (BMI), habitual smoking, habitual drinking, diabetes mellitus, hypercholesterolemia, past history of cardiovascular disease and serum sodium. Respectively, 30 and 35 subjects had HBP hypertension among subgroups with high $(n=257)$ and low $(n=257)$ sodium intake. ${ }^{*} P<0.01$.

with low sodium intake (Figure 1). There were significant interactions between sodium intake and $\log P R A$ or $\operatorname{logARR}$ on the prevalence of HBP hypertension (Figure 1, $P=0.03$ ). LogPAC was not consistently associated with HBP hypertension. We then analyzed HBP as a continuous variable and observed consistent results. In subjects with high sodium intake, a 1 s.d. decrease in $\log P R A$ was associated with systolic HBP $(\beta=-2.47, P=0.0007)$ and diastolic HBP $(\beta=-1.71$, $P=0.0002)$ in fully adjusted models. A 1 s.d. increase in logARR was also associated with HBP levels $(\beta=2.43, P=0.0006$ for systolic $B P$; $\beta=1.81, P<0.0001$ for diastolic BP). However, in subjects with low sodium intake, $\log \mathrm{PRA}$ and $\log \mathrm{ARR}$ were no longer associated with HBP $(P \geqslant 0.1)$.

In the subgroup of subjects with high sodium intake, individuals with HBP hypertension $(n=30)$ had significantly lower PRA and higher ARR than those with HBP normotension $(n=227)$ after adjustment for sex and age (Figure 2). Adjustments for potassium intake or serum potassium levels did not change the results (data not shown).

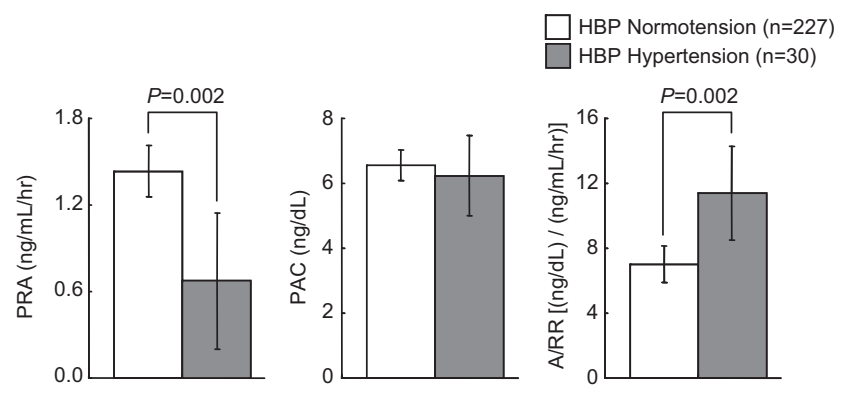

Figure 2 Levels of plasma renin activity (PRA), plasma aldosterone concentration (PAC) and aldosterone-to-renin ratio (ARR) in home blood pressure (HBP) normotensives and hypertensives. Means (95\% confidence intervals) of PRA, PAC and ARR in a subgroup of subjects with high sodium intake (above the median of $4822 \mathrm{mgday}^{-1}$ ) after adjusting for sex and age. Home hypertension was at least $135 / 85 \mathrm{~mm} \mathrm{Hg}$.

We also performed stratified analyses. Sex (men/women), age $\left(<65 / \geqslant 65\right.$ years), BMI $\left(<25 / \geqslant 25 \mathrm{~kg} \mathrm{~m}^{-2}\right)$, total energy intake (below or above median of $1790 \mathrm{kcalday}^{-1}$ ) or potassium intake (below or above median of $2427 \mathrm{mg} \mathrm{day}^{-1}$ ) did not significantly affect the associations of $\log \mathrm{PRA}, \log \mathrm{PAC}$ and $\log \mathrm{ARR}$ with the prevalence of HBP hypertension ( $P>0.05$ for all interactions).

\section{DISCUSSION}

The present cross-sectional study found that ARR was significantly and independently associated with the prevalence of HBP hypertension in a general population, after adjusting for sex, age, BMI, smoking and drinking status, hypercholesterolemia, diabetes mellitus, history of cardiovascular disease, serum sodium level and dietary sodium intake. Furthermore, the association of ARR with HBP hypertension was strengthened for subjects with high sodium intake.

To date, a few general population studies ${ }^{2,3}$ have reported on the association of ARR with BP, and these studies ${ }^{2,3}$ were based solely on CBP. To our knowledge, ours is the first study to report on the association of ARR with HBP hypertension in a general population. HBP, a technique that makes it possible to obtain multiple measurements under well-controlled conditions, has been reported to be more reliable than CBP measurement because it avoids both observer and regression dilution biases and eliminates the white-coat effect or diurnal variation. ${ }^{12,24,26}$ In fact, we observed that ARR was more 
closely related to hypertension diagnosed by HBP than by CBP (Table 2). Consequently, HBP measurements should be included in clinical studies to identify aldosterone effects on BP independent of CBP.

In the analyses of all subjects, our findings are in agreement with a Framingham Offspring study ${ }^{2}$ that found that the prevalence of CBP hypertension was associated with higher ARR levels in a stepwise regression analysis of 3326 subjects. However, regarding the interaction between sodium intake and ARR on hypertension, one nested case-control study ${ }^{3}$ of 1984 subjects from a general French population provided different result from ours. They reported that ARR was associated with progression of CBP hypertension only in the lowest tertile of dietary sodium intake $\left(<2737 \mathrm{mg} \mathrm{day}^{-1}\right){ }^{3}$ The differences in study design (prospective vs. cross-sectional) and BP measurements (CBP vs. HBP) may have influenced the variation in results between the French study and our findings.

\section{Salt-sensitive hypertension}

After adjustment for possible confounding factors, ARR was significantly associated with the prevalence of HBP hypertension, especially for subjects with high sodium intake. These results indicate that salt sensitivity may have a role in the association between high ARR and HBP hypertension. It is thought that salt-sensitive hypertension includes two main types, that is, low-renin hypertension (also called relative aldosterone excess) and non-modulating hypertension. We discuss the possible implications of these two subtypes of hypertension below.

\section{Relative aldosterone excess}

In the present study, low PRA was associated with an increased prevalence of HBP hypertension (Table 2 and Figure 1), and HBP hypertensive subjects had lower PRA than normotensive subjects in the high sodium intake subgroup (Figure 2). Thus, these HBP hypertensive subjects with high sodium intake were considered to have low-renin hypertension. ${ }^{27}$ In most cases, low-renin hypertensive patients have a sodium-volume-dependent hypertension, ${ }^{27,28}$ implying that sodium-volume overload had occurred in HBP hypertensive subjects with high sodium intake in our study. In response to suppressed renin and volume expansion, a decrease in aldosterone would be expected in normal subjects. However, in the present study, PAC was not decreased in HBP hypertensive subjects with high sodium intake (Figure 2). Such a form of low renin and normal aldosterone is called relative aldosterone excess, which is responsible for hypertension because of inappropriate sodium and fluid retention or impaired nitric oxide. ${ }^{28,29}$ Therefore, our findings suggest that even in the general population, relative aldosterone excess may have an important role in salt-sensitive hypertension.

Some patients with primary aldosteronism have a low renin level but a normal aldosterone level. Thus, we cannot exclude the possibility that primary aldosteronism was present in some individuals with HBP hypertension in the high sodium intake subgroup. Weak mineralocorticoid excess might be related to the suppression of renin as it is reported that low renin was induced not only by aldosterone but also by mineralocorticoids, such as 11-deoxycorticosterone, 18-hydroxydeoxycorticosterone, 18-hydroxycortisol and 18-hydroxycorticosterone. ${ }^{30}$ Although it is thought that aldosterone secretion is also suppressed by mineralocorticoid excess, ${ }^{30}$ these hormones might have affected ARR levels in the present study.

\section{Non-modulating hypertension}

In normal subjects, an increase in sodium intake produces an increase in renal blood flow, thereby enhancing the ability of the kidney to excrete sodium. ${ }^{31}$ However, individuals with non-modulating hypertension do not show increased renal blood flow when sodium intake is increased. ${ }^{31}$ Therefore, they would retain sodium and water, which could underlie their salt sensitivity. ${ }^{31}$ Individuals with nonmodulating hypertension most often have normal or high renin levels. ${ }^{31}$ Thus, it is less likely that non-modulating hypertension contributed to our results of HBP hypertension with high sodium intake.

It is suggested that aldosterone excess is associated with obesity or insulin resistance. ${ }^{32}$ Our study also showed that BMI is associated with tertiles of ARR (Table 1). Although BMI might not affect the association between ARR and the prevalence of HBP hypertension, there is a possibility that relative aldosterone excess may contribute to obesity or insulin resistance (and vice versa) in a general population. Further prospective study is needed to clarify this issue.

This study has several limitations. First, the study population predominantly included middle-aged, elderly and female individuals with relatively high salt intake; the mean salt intake was $14.6 \mathrm{~g} \mathrm{day}^{-1}$. These imbalances might, to some extent, limit the external validity of the findings. Second, this study was cross-sectional, and thus causeand-effect relations of ARR on hypertension cannot be made. Third, subjects underwent blood sampling between 0900 and $1100 \mathrm{~h}$ or between 1300 and $1500 \mathrm{~h}$ and most often had not fasted. Therefore, both PRA and PAC might be affected by time of day and diet before the health check-up. Fourth, data on urinary sodium and potassium excretion were not collected. We obtained data on sodium intake from the 1-year food-frequency questionnaire, which has been validated by a standard procedure from the viewpoint of nutriology. ${ }^{21,22}$ However, the validation was not confirmed by direct comparison with urinary sodium excretion. This might weaken the interaction between logARR and sodium intake on HBP observed in this study. Fifth, we did not have information about adrenocorticotropic hormone, mineralocorticoid hormones other than PAC, urinary excretion of aldosterone or these metabolites. Sixth, some of the findings may have been the result of chance because of multiple comparisons and, therefore, they need to be reproduced in future studies.

In conclusion, the study provides evidence for relative aldosterone excess contributing to salt-sensitive hypertension even in a general population. These results suggest that relative aldosterone excess or low-renin hypertension contributes to salt-sensitive hypertension in the general population. Prospective studies based on HBP are needed to determine whether ARR predicts the progression of BP, target organ damage and prognosis.

\section{CONFLICT OF INTEREST}

The authors declare no conflict of interest.

\section{ACKNOWLEDGEMENTS}

We are grateful to the residents of Ohasama Town, all related investigators and study staff, and staff members of the Ohasama Town Government, Ohasama Hospital and Iwate Prefectural Stroke Registry for their valuable support on this project. This study was supported in part by Grants for Scientific Research (15790293, 16590433, 17790381, 18390192, 18590587, 19590929, 19790423, 20590629, 21390201, 21591016, 22590767 and 22790556) from the Ministry of Education, Culture, Sports, Science, and Technology, Japan; Grant-in-Aid (H17-Kenkou-007, H18-Junkankitou(Seishuu)-Ippan-012, and H20-Junkankitou(Seishuu)-Ippan-009, 013) from the Ministry of Health, Labor and Welfare, Health and Labor Sciences Research Grants, Japan; Grant-in-Aid for Japan Society for the Promotion of Science (JSPS) fellows (16.54041, 18.54042, 19.7152, 20.7198, 20.7477 and 20.54043); Health Science Research Grants and Medical Technology Evaluation Research Grants from the Ministry of Health, Labor and Welfare, Japan; Japan Atherosclerosis Prevention Fund; Uehara Memorial Foundation; Takeda Medical Research Foundation; National Cardiovascular Research Grants; and Biomedical Innovation Grants. 
1 Vasan RS, Evans JC, Larson MG, Wilson PW, Meigs JB, Rifai N, Benjamin EJ, Levy D. Serum aldosterone and the incidence of hypertension in nonhypertensive persons. $N$ Engl J Med 2004; 351: 33-41.

2 Newton-Cheh C, Guo CY, Gona P, Larson MG, Benjamin EJ, Wang TJ, Kathiresan S, O'Donnell CJ, Musone SL, Camargo AL, Drake JA, Levy D, Hirschhorn JN, Vasan RS. Clinical and genetic correlates of aldosterone-to-renin ratio and relations to blood pressure in a community sample. Hypertension 2007; 49: 846-856.

3 Meneton P, Galan P, Bertrais S, Heudes D, Hercberg S, Menard J. High plasma aldosterone and low renin predict blood pressure increase and hypertension in middle-aged Caucasian populations. J Hum Hypertens 2008; 22: 550-558.

4 Ljungman S, Aurell M, Hartford M, Wikstrand J, Berglund G. Blood pressure in relation to the renin-angiotensin-aldosterone system. Acta Med Scand 1982; 211: 351-360.

5 Genest J, Nowaczynski W, Boucher R, Kuchel 0, Rojo-Ortega JM. Aldosterone and renin in essential hypertension. Can Med Assoc J 1975; 113: 421-431.

6 Wisenbaugh PE, Garst JB, Hull C, Freedman RJ, Matthews DN, Hadady M. Renin, aldosterone, sodium and hypertension. Am J Med 1972; 52: 175-186.

7 Walker WG, Whelton PK, Saito H, Russell RP, Hermann J. Relation between blood pressure and renin, renin substrate, angiotensin II, aldosterone and urinary sodium and potassium in 574 ambulatory subjects. Hypertension 1979; 1: 287-291.

8 Tolagen K. Aldosterone in primary hypertension relationship to plasma renin activity and urinary electrolytes and a comparison with normotensive subjects. Scand J Clin Lab Invest 1978; 38: 487-493.

9 Tiu SC, Choi CH, Shek CC, Ng YW, Chan FK, Ng CM, Kong AP. The use of aldosteronerenin ratio as a diagnostic test for primary hyperaldosteronism and its test characteristics under different conditions of blood sampling. J Clin Endocrinol Metab 2005; 90: 72-78.

10 Foo R, O'Shaughnessy KM, Brown MJ. Hyperaldosteronism: recent concepts, diagnosis, and management. Postgrad Med J 2001; 77: 639-644.

$11 \mathrm{Lim}$ PO, Jung RT, MacDonald TM. Is aldosterone the missing link in refractory hypertension?: aldosterone-to-renin ratio as a marker of inappropriate aldosterone activity. J Hum Hypertens 2002; 16: 153-158.

12 O'Brien E, Asmar R, Beilin L, Imai Y, Mallion JM, Mancia G, Mengden T, Myers M, Padfield P, Palatini P, Parati G, Pickering T, Redon J, Staessen J, Stergiou G, Verdecchia P. European Society of Hypertension recommendations for conventional, ambulatory and home blood pressure measurement. J Hypertens 2003; 21: 821-848.

13 Ohkubo T, Asayama K, Kikuya M, Metoki H, Hoshi H, Hashimoto J, Totsune K, Satoh H, Imai Y. How many times should blood pressure be measured at home for better prediction of stroke risk? Ten-year follow-up results from the Ohasama study. J Hypertens 2004; 22: 1099-1104.

14 Hara A, Ohkubo T, Kikuya M, Shintani Y, Obara T, Metoki H, Inoue R, Asayama K, Hashimoto T, Harasawa T, Aono Y, Otani H, Tanaka K, Hashimoto J, Totsune K, Hoshi H, Satoh H, Imai Y. Detection of carotid atherosclerosis in individuals with masked hypertension and white-coat hypertension by self-measured blood pressure at home: the Ohasama study. J Hypertens 2007; 25: 321-327.

15 Kikuya M, Hozawa A, Ohokubo T, Tsuji I, Michimata M, Matsubara M, Ota M, Nagai K, Araki T, Satoh H, Ito S, Hisamichi S, Imai Y. Prognostic significance of blood pressure and heart rate variabilities: the Ohasama study. Hypertension 2000; 36: 901-906.

16 Imai $Y$, Satoh $H$, Nagai K, Sakuma M, Sakuma H, Minami N, Munakata M, Hashimoto J, Yamagishi T, Watanabe N, Yabe T, Nishiyama A, Nakatsuka H, Koyama
$\mathrm{H}$, Abe K. Characteristics of a community-based distribution of home blood pressure in Ohasama in northern Japan. J Hypertens 1993; 11: 1441-1449.

17 Mulatero P, Dluhy RG, Giacchetti G, Boscaro M, Veglio F, Stewart PM. Diagnosis of primary aldosteronism: from screening to subtype differentiation. Trends Endocrinol Metab 2005; 16: 114-119.

18 Imai Y, Abe K, Sasaki S, Minami N, Munakata M, Sakuma H, Hashimoto J, Sekino H, Imai K, Yoshinaga K. Clinical evaluation of semiautomatic and automatic devices for home blood pressure measurement: comparison between cuff-oscillometric and microphone methods. J Hypertens 1989; 7: 983-990.

19 Ogihara T, Kikuchi K, Matsuoka H, Fujita T, Higaki J, Horiuchi M, Imai Y, Imaizumi T, Ito S, Iwao H, Kario K, Kawano Y, Kim-Mitsuyama S, Kimura G, Matsubara H, Matsuura H, Naruse M, Saito I, Shimada K, Shimamoto K, Suzuki H, Takishita S, Tanahashi N, Tsuchihashi T, Uchiyama M, Ueda S, Ueshima H, Umemura S, Ishimitsu T, Rakugi H. The Japanese Society of Hypertension Guidelines for the Management of Hypertension (JSH 2009). Hypertens Res 2009; 32: 3-107.

20 Kuzuya T, Nakagawa S, Satoh J, Kanazawa Y, Iwamoto Y, Kobayashi M, Nanjo K, Sasaki A, Seino Y, Ito C, Shima K, Nonaka K, Kadowaki T. Report of the Committee on the classification and diagnostic criteria of diabetes mellitus. Diabetes Res Clin Pract 2002; 55: 65-85.

21 Tsubono Y, Ogawa K, Watanabe Y, Nishino Y, Tsuji I, Watanabe T, Nakatsuka H, Takahashi N, Kawamura M, Hisamichi S. Food frequency questionnaire and a screening test. Nutr Cancer 2001; 39: 78-84.

22 Utsugi MT, Ohkubo T, Kikuya M, Kurimoto A, Sato RI, Suzuki K, Metoki H, Hara A, Tsubono Y, Imai Y. Fruit and vegetable consumption and the risk of hypertension determined by self measurement of blood pressure at home: the Ohasama study. Hypertens Res 2008; 31: 1435-1443.

23 Matsuo S, Imai E, Horio M, Yasuda Y, Tomita K, Nitta K, Yamagata K, Tomino Y, Yokoyama $H$, Hishida A. Revised equations for estimated GFR from serum creatinine in Japan. Am J Kidney Dis 2009; 53: 982-992.

24 Imai Y, Otsuka K, Kawano Y, Shimada K, Hayashi H, Tochikubo O, Miyakawa M, Fukiyama K. Japanese Society of Hypertension (JSH) guidelines for self-monitoring of blood pressure at home. Hypertens Res 2003; 26: 771-782.

25 Mattsson C, Young Jr WF. Primary aldosteronism: diagnostic and treatment strategies. Nat Clin Pract Nephrol 2006; 2: 198-208.

26 Asmar R, Zanchetti A. Guidelines for the use of self-blood pressure monitoring: a summary report of the First International Consensus Conference. Group Evaluation \& Measure of the French Society of Hypertension. J Hypertens 2000; 18: 493-508.

27 Freel EM, Connell JM. Mechanisms of hypertension: the expanding role of aldosterone. J Am Soc Nephrol 2004; 15: 1993-2001.

28 Duffy SJ, Biegelsen ES, Eberhardt RT, Kahn DF, Kingwell BA, Vita JA. Low-renin hypertension with relative aldosterone excess is associated with impaired NO-mediated vasodilation. Hypertension 2005; 46: 707-713.

29 Funder JW. Relative aldosterone excess: relative to what? Hypertension 2005; 46: 643-644.

30 Stewart PM. Mineralocorticoid hypertension. Lancet 1999; 353: 1341-1347.

31 Williams GH, Hollenberg NK. Non-modulating hypertension. A subset of sodiumsensitive hypertension. Hypertension 1991; 17: I81-|85.

32 Whaley-Connell A, Johnson MS, Sowers JR. Aldosterone: role in the cardiometabolic syndrome and resistant hypertension. Prog Cardiovasc Dis 2010; 52: 401-409. 